\title{
The Role of Social Support and Demographic Variables in Promoting Identity Achievement: The Case of College Students in Gondar, Amhara Region, Ethiopia
}

\author{
Yitades Tesfaye \\ Department of Psychology, Institute of Education and Behavioural Science, Ambo University, Ambo, Ethiopia
}

Email address:

tyitades@yahoo.com

To cite this article:

Yitades Tesfaye. The Role of Social Support and Demographic Variables in Promoting Identity Achievement: The Case of College Students in Gondar, Amhara Region, Ethiopia. American Journal of Applied Psychology. Vol. 6, No. 6, 2017, pp. 173-182.

doi: 10.11648/j.ajap.20170606.16

Received: August 26, 2017; Accepted: September 19, 2017; Published: November 30, 2017

\begin{abstract}
The purpose of this study was to investigate the status of identity achievement, and its relationship with social support of young adults in college. In addition, the study was aimed to investigate gender, and year of staying in college on identity achievement. Participants of this study were a total of 291 (114 male and female 177) first, second and third year college students of Gondar College of Teacher Education, who were selected using stratified sampling method. This study was conducted using Likert type scale i.e., Functional Identity Scale and Multidimensionality Scale of Adequacy of Social Support. Findings indicated that young adult college students had a moderate and above level of identity achievement. It was also found that the level of social support was strongly associated with identity achievement. Regarding years of stay in college, third, second and first year students found the absence of statistical mean difference on identity achievement. Finally, there was no gender difference in the identity achievement profile. Possible implications were discussed.
\end{abstract}

Keywords: Identity Achievement, Social Support, Young Adult College Students

\section{Introduction}

\subsection{Background}

Young adulthood (roughly 18-26 years) is a period when individuals actively choose between various possibilities such as mate selection, work, and worldwide views [4]. Contemporary studies enhance the understanding of developmental dimensions of this distinctive, yet under searched, period of the life course. This period has its own features which may include at least five defining characteristics: identity exploration processes in the area of love, world and world views instability, being self focused, feeling somewhere in between and looking forward and experiencing various future possibilities of life [5].

Most students in college are young adults [19]. This is a period when rapid changes take place in individuals' life due to their exposure to new ideas and involvement in intimate relationships [5]; [20]; [13]; [40]. Over the course of college years, they undergo opportunities of psychosocial development and learning experiences that expand their cognitive, emotional, and social adaptive capacities [46]; [38]. Studies have identified that young adult college students retained responsible behavior, autonomous decision-making and financial independence. These are viewed as the most important marker or developmental indicator of the young adult transition [3]. As Chickering \& Reisser, [15], pointed out traditional aged students in college explore and earn the possibilities of social competence, develop their autonomy patterns and identity, as well as formation of intimate relationship finally persist in to adulthood. Most often, they develop along each of these domains simultaneously [25]. Based on this numerous changes, it might be expected that identity style would receive a major stimulus towards the growth of young adult students in college.

However, for number of reasons, many young adults are unable to take the steps necessary to move forward in forming their identity [2]. As a result, movement along these 
dimensions may vary from student to student and will finally face these challenges [39]. Arnett, cited in [26], spelled out that while individuals in this age group (18-26 years) are expected to show progress in their individuation and selfdefinition as exhibited by their capacity to develop mature intimate relationships and maintain independence, the majority tend to postpone accomplishing these tasks. Throughout their transition to adulthood, they may face difficulties in matching their achievement of expectations for education, work, and relationships with real life. Some individuals also suffer from difficulty in interaction with others, or maintaining a friend because they lack the social skills for facing the challenges [21]. In turn, identity establishment tasks can be a disorienting and difficult experience for them rather than a normal part of their development [26]. This implies that there may be a deterioration of development patterns and the resolution of the issues either prior or after their expected emergence in the life course.

\section{Theoretical Perspectives of Social Support and identity} Style

Different factors are assumed to affect the development of one's identity. Some suggest the support and opportunities offered by individual's environment have large influence on identity formation. Considering the impact of this factor is crucial to understand the formation of identity. Social support provides the most significant environmental resources such as provision of strong social attachments. This makes an individual to be able to exchange helpful resources and develop a feeling of having supportive relationship and behaviors [45]. Parents, friends, siblings, relatives, and teachers are important sources of social support during young adulthood in college [6]; [48]. Empirical findings revealed that parents and friends are the most important sources for the development of one's future life orientation, current events, and activities, relationships, and friendship formation [44]. The social support theory views that the social support provided by significant persons through advice and reassurance enhances adaptation to stressful situation [26].

Some contemporary researches elucidated that people may have a number of social needs or provisions that are necessary for them to feel sufficiently supported. There are evidences that social support may be protective and can improve the well-being of young adult college students through the psychological effects of the presence of other, preventing isolation, through being a valued part of the network, receiving a sign of love and understanding, and being secure of help when it is needed [42]; [59]. This can foster not only confidence, self-assurance and feelings of worth, but also security and control over oneself and to the environment which are components of identity formation [44]. The study conducted on Somali young adults identified that most individuals reported strong family support promoted their positive behaviors and developmental outcomes [19]. Social support received from teachers play prominent role in the development of students. Strong positive interpersonal relationships are beneficial, because they function as a source of comfort and safety throughout the multiple life changes that occur during this stage of development [37]. On the contrary, continual persons who lose the social support have more developmental difficulties than those who have access to support [19]. Based on the above mentioned empirical findings, it is possible to conclude that young adult college students who have access to social support have opportunities to facilitate their psychosocial profile than those who lacks its availability. Families, friends, and other significant persons who provide positive emotional, informational, and instrumental supports potentially contribute to healthy patterns of psychosocial development of young adult students in college.

In the Ethiopia context, local researches on the issues of psychosocial profile of young adult college students and the contribution of social support are very limited. Nevertheless, according to Eric et al. [19], most Somali young adults widely reported that they faced many psychosocial developmental challenges. Moreover, young people students may move back and forth between transitions and inconsistent to form and maintain healthy relationships. Others may rotate between the period of work and unemployment or live independently at times and then retire to live with their parents [23]; [13]. Local studies conducted among late adolescent preparatory students found out problematic relationship, experiencing feeling of worrisome, being bored with life and the world around them. More than half of students reported feeling lonely and depression [43]. Besides, high level of drug addiction was observed among young adult college students [57]; [52]. These all facts are possible symptoms of diffused identity. This condition requires a systematic research on the identity achievement profile of young adult student's in college.

In light of lack of knowledge in the area and implications of the issue in Ethiopia context, the present study is designed to assess the relative contribution of social support in the identity achievement profile of young adult Ethiopian students in Gondar College of Teacher Education.

\subsection{Problem Statement}

Psychological researches have explored the dimensions of psychosocial profile of young adult college students. However, social support as a conditioning factor of identity achievement has not yet been adequately explored as compared with other variables such as; depression, loneliness, academic failure, family problem, substance abuse, and others. In addition, children and adolescents have been highly emphasized; however, the young adult period has been given little attention. Very recently, different researches have been conducted on young adult, particularly focusing on the emerging adulthood as a separate stage of development in North America and Europe. Nevertheless, in Ethiopia young adulthood as a course and as an issue has become newer.

Although fewer investigations have been conducted in different parts of the world concerning the identity achievement and its relation with social support and sociodemographic variables, the present researcher has not found 
any research done on the issue to be cited in the Ethiopian context. For example, some researches done as a requirement for fulfilling MA degree in psychology on the relationship between social identity and interpersonal relationship, the influence of inter ethnic attitude on enter ethnic quality of interaction, career choice of students at preparatory school, emotional intelligence and its link with some demographic variables and academic achievement assessment of the contribution of peer education for HIV infection risk reduction among late adolescents and young adults (e.g. [18], [1], [28], [31] and [53]. However, one can hardly illustrate the clear relationship between social support and socialdemographic variables: gender, year of staying in college and identity achievement profile that is typical for Ethiopian young adult college students.

Lastly, it has been well recognized by psychologists due to the deep interwoven nature of development and within contextual cultural characteristics, which serve as a mediating factor in bringing variations among individuals' dimensions of psychosocial development [34]. Due to this reason, what was found abroad may not show the reality in the Ethiopian context. If those arguments make sense then there is a need to study how social support and sociodemographic variables including gender, year of staying in college, as well as socioeconomic status of the family relate to the dimensions of the psychosocial profile of young adult students in Gondar College of Teacher Education.

\subsection{Research Questions}

The availability of social support is a determinant factor of identity formation young adult college students. In addition, socio-demographic factors plays role in the development of psychosocial profile of the students as well. Hence, this study is designed to find out answers to the following questions:

1. What is the status of identity achievement of young adult college students?

2. Is there association between social support and identity achievement of young adult college students?

3. Does identity achievement vary across sociodemographic variables including gender, and year of staying in college?

\subsection{Objectives}

The general objective of this study is to investigate the role of social support in the psychosocial profile of young adult college students. More specifically, it attempts to:

1. Identify the status of identity achievement of young adult college students in Gondar College of Teacher Education.

2. Investigate the association between social support and identity achievement of young adult college students.

3. Examine gender differences in the identity achievement among young adult college students.

4. Identify differences in the identity achievement among young adult students by their year of staying in college.

5. Recommend possible solutions based on the findings of the study.

\subsection{Operational Definitions}

Identity: involves on discovering "who am I?" which entails being able to know oneself and attitudes towards oneself and constitutes coherent outlook of what one's personality is and how it fits in a social context including clarification of one's roles and lifestyle, recognition of the self in light of reactions from others, self-confidence and acceptance, and personal integration.

Social Support: refers to the experience being valued, respected, cared about, and loved by others who are present in one's life. It may come from different sources including family, friends, and other significant persons.

Young adult College Students: It is restricted to those college students whose age were between 18-26 years old.

Demographic Variables: It refers gender and year of staying in college.

\subsection{Significance}

It is relevant to look into the problem to have more information about the issue that will help for families, teachers, counselors, policy makers and organizations working with young adult college students to design intervention measures. In addition, this study can serve as a springboard for training institutions, colleges, government agencies, and educational planners to mold their training program in a way that takes into account the trainee's identity achievement. Finally, there are no enough studies on the dimensions of the psychosocial profile of the students in Ethiopian context. The result can enable them aware of the identity achievement and create conducive environment to facilitate growth to more mature and complex level of functioning.

\section{Methods}

\subsection{Research Design}

Correlational research design was used to examine the relationships between social support and the identity formation of young adult college students. Social support and socio-demographic characteristics were independent variables, whereas profile of identity formation was the dependent variables.

\subsection{Study Area}

This study was conducted in Gondar College of Teachers' Education (Gondar Town) on young adult college students. Gondar is located in the northern part of Ethiopia (Amhara region), distant 750 k.m from Addis Ababa. Most college students have been admitted from districts under the zones of the national regional state of Ethiopia. Many of the students live alone, going away from the home background of their family.

This condition provides them the opportunities to get 
freedom relatively from their parent's control, live their independent life, and create new opportunities and challenges

The rational for selecting this problem and the study area site are:

1. The problem concerned with the dimensions of psychosocial development is not sufficiently studied in Ethiopia especially among young adult college students.

2. It is obvious that most of the researcher prefer to conduct their studies in the main capital city, Addis Ababa, due to lack of interest to go out in other areas.

3. The student researcher's experience and observation of the problem at higher educational level

Therefore, by considering these all, the student researcher chooses Gondar College of Teacher Education to conduct this study.

\subsection{Population}

Students of Gondar College of Teacher Education, whose age ranges from 18-26, were target population. First, second and third year students were included in the study. These three (all) levels were chosen for various reasons. First, conducting studies on students of different year level enables to see its contribution over time. Other things being equal, including participants from different levels allow us to get participants of different age levels. This in turn, helps us to see differences in identity achievement profile across different age groups. Secondly, sampling participants at different age and year of staying in college represents the powerful way to enhance external validity or generalizability of the study.

\section{Sampling}

Gondar College of Teacher Education has been offering two programs; linear and cluster programs. In the linear program, there are nine departments; namely Amharic, English, Mathematics, Physics, Chemistry, Biology, History, Geography, and Aesthetics. The cluster program includes five departments: Language, Mathematics, Natural Science, Social Science, and Aesthetics, which are given for regular college students. Five departments were randomly selected from linear program. These were Amharic, English, Biology,
Geography, and History.

Proportionately, three departments were randomly selected from the cluster program. These were Mathematics, Natural Science, and Social Science. Then these departments were stratified based on year on staying in college. First, second and third year students were considered in this study. Proportional stratified sampling was applied to select participants of the study from the population.

Level of staying in college by year, name, age, and gender were obtained from all departments of the two programs. The student researcher and assistant data collectors listed out all students' with their department, college year, and gender. Then, by using student's list, participants were taken through simple random sampling (lottery method). The total number of students found in the eight departments was 1280 (482 male and 798 female). Out of 1280 regular students enrolled in the college, 306 students from the three year levels (first, second and third) were selected. The sample size was determined based on the recommendation of Krejcie and Morgan [24] for correlation research design.

These participants were proportionally selected using the following steps:

1. As the information taken from the administration officer of the institution shows, the total number of young adult college students is 1280 .

2. The proportion for selection was determined by computing the ratio of the required sample $(t)$ to the population $(\mathrm{T})$ of the study. Proportion $\mathrm{t} / \mathrm{T}$, $306 / 1280=0.2391$

3 . The number of members in each stratum was multiplied by the obtained proportion to get the number of young adult students from each educational year level that were included in the sample of the study

The sample selection considered the proportions of males and females, and year of staying in college using the above mentioned steps [16]. Among the total 306, 15 respondents did not complete the questionnaire appropriately. These were excluded from the analysis. Therefore, the analysis was based on the data obtained from two hundred ninety one respondents. (See Table 1 below for the details)

Table 1. Distribution of sample size.

\begin{tabular}{|c|c|c|c|c|c|c|}
\hline \multirow{2}{*}{ Year of staying in college } & \multicolumn{2}{|c|}{ Population } & \multirow{2}{*}{ Total } & \multicolumn{2}{|l|}{ Sample } & \multirow{2}{*}{ Total } \\
\hline & Male & Female & & Male & Female & \\
\hline First Year & $124(31 \%)$ & $276(69 \%)$ & 400 & $32(33 \%)$ & $64(67 \%)$ & $96(33 \%)$ \\
\hline Second Year & $207(36 \%)$ & $353(64 \%)$ & 560 & $43(34 \%)$ & $83(66 \%)$ & $126(44 \%)$ \\
\hline Third Year & $150(47 \%)$ & $169(53 \%)$ & 319 & $39(56 \%)$ & $30(44 \%)$ & $69(23 \%)$ \\
\hline Total & & & 1279 & & & 291 \\
\hline
\end{tabular}

\subsection{Variables}

The independent variables include social support and socio-demographic factors such as gender, and year of staying in college. In this study, the dependent variable was identity achievement.

\subsection{Tools}

Data were collected using self-administered questionnaire for all the variables. The first part consists of demographic variables, such as age, gender and year of staying in college. The availability of social support was measured using a 12 items multidimensional scale of perceived social support 
(MPASS) that was originally developed by Zimet [54]. Finally, Functional Identity Scale was used to assess the identity achievement profile of college students.

\subsection{Procedures}

\subsubsection{Construction}

\section{Test for Identity Achievement:}

The 15 items Functions of Identity Scale (FIS) was used to measure how young adult college student's sense of self was constructed. Serafini and Adams [41] originally developed this scale. The functions of identity are theoretically arranged in line with Erikson's notion of an "optimal identity" [17]. The function of identity theoretical framework seeks to describe how identity serves to provide individuals with a sense of structure with which to understand self-relevant information as well as a sense of harmony between chosen values, beliefs, and commitments. Besides, it seeks to describe a future orientation where goals may be pursued in the context of achieving a sense of a possible self and fostering a congruency between one's view of oneself in the present and in the future. Lastly, FIS attempt to see a goal orientation where individuals actively pursue goals that are congruent with an established sense of self or personal identity; and a sense of personal control, free will, or agency that enables active self-regulation in the process of setting and achieving goals, moving toward plans, and processing experiences in ways that are self-relevant.

Respondents were asked to indicate on a 5-point Likert scale how well each of the statements describes them $(1=$ never, $2=$ seldom, $3=$ sometimes, $4=$ often, and $5=$ always $)$. However, based on the research identified difficulties of clearly understanding the difference between the five intervals specially when it was translated in Amharic during pilot study before collecting the main data and the recommendation of experts in the area, the researcher modified into 4-point likert scale and describe them $(1=$ never, $2=$ sometimes, $3=$ often, $4=$ always) to minimize its vagueness. Serafini and Adams, [41] recommend researchers to use the summed scores of the scale to observe the full distribution of variance in a given sample. Originally, the reliability of the instrument was $\alpha=.77$ [41]. Scores can range from 15 to 75 , with the highest score representing the highest level of functions of identity scale.

\section{Social Support}

With a little modification to fit the cultural context of participants of the study, multidimensional scale of perceived adequacy social support was adapted and used to assess the social support status of participants. The multidimensionality scale of adequacy of social support, that was originally developed by Zimet, et al., [55], employed to measure the perceived adequacy of social support. It was a 12 items scale, rated on a 7-point Likert scale ranging from (1) very strongly disagrees to (7) very strongly agree. Carmen [14] modified it to a 5-point Likert scale as they thought that participants may have a difficult time differentiating between the points on the scale, and felt that the 5-point scale would be more culturally appropriate and comprehensible.
The multidimensional scale of social support was used by many researchers who were looking for a short, clear and accurate scale to measure social support from family, friends and significant others (e.g. [26]. Here, other significant refer to persons beyond family and friends [11]. Multidimensional perceived adequacy social support scale was used in the study because of its validity and reliability that was conformed after conducting research with many different samples (e.g. [30]; [49]; [26]. Consequently, it is a valid and reliable instrument for measuring social support across cultures. The reliability of these sub-scales originally was $0.78,0.76$, and 0.69 respectively [55]. During the analysis participants over all raw score on social support further categorized in to three groups. Ashley [8], recommended that based on scores from the Multidimensional Scale of Perceived Social Support, participants should be placed into a total social support category (low, medium, or high) depending on their total score of perceived social support. The researcher used the standardized scoring guideline that was suggested by Carmen [14]. The scoring guidelines (standard values of normal distribution) indicated that an overall score of: 12-29 reflects low social support, 30-44 reflects medium levels of social support, and 45-60 reflects high social support.

\subsubsection{Validation}

\section{Expert Judgment}

The content validity of the adapted instruments was evaluated by graduate students from different discipline of psychology (social, measurement, and developmental psychology) and language department at Addis Ababa University. Then, both the Amharic and English version of 81 items were assigned to six judges. (one literature and linguistic masters, one developmental psychology $\mathrm{PhD}$, two developmental psychology Masters, one measurement and evaluation and one social psychology students) to compare the translation compatibility with the original language and sort them out in terms of how proper the descriptions are for identity achievement and social support. Before the judges make categorization of the items used to measure, the researcher has spent enough time in explaining and briefing its objective to the judges. In addition, the experts were asked to give their replies under the alternative 'relevant', 'irrelevant' and state their remarks. Besides, they were asked to give their comments regarding items to be included, irrelevant, and over emphasized items. Identity status and social support scales, according to their judgment, were approved because of their compatible language translation, relevance, and content validity. Therefore, the researcher used the entire items with little modification.

\section{Pilot test}

Before the actual data collection from respondents, a pilot test was conducted. Accordingly, the Amharic version of questionnaires was tried out for two days among 25 randomly selected students at Kotebe University College later called Kotebe Metropolitan University, where similar settings practically could go together with Gondar College of 
Teacher Education students. The sample subjects were taken purposely to represent each cluster of sex and year of staying in college. One of the most commonly used indicators of internal consistency is Cronbach's alpha. Ideally, as a rule of thumb, Cronbach alpha coefficient of a scale should be .7 and above [35]. For that matter, the researcher used Cronbach alpha to determine the reliability of identity achievement and social support items.

Table 2. Reliability test result of each variable.

\begin{tabular}{lll}
\hline Variables & Chronbach alpha & No. of items \\
\hline Identity Status & 0.78 & 15 \\
Social support & 0.81 & 12 \\
Total Scale & 0.806 & 27 \\
\hline
\end{tabular}

Based on the feedback obtained from the result of pilot test of reliability, as it can be seen from the Table above all the scale met the desired reliability coefficient. Thus, the instrument was found important to collect data for the main study.

\subsubsection{Administration}

Initial orientation was provided to assistant data collectors on how to handle questions that may be raised from respondents. In addition, the researcher arranged conditions to make participants feel free while giving responses with the help of administrative officials and instructors. They were also assured that the responses provided were confidential and any information would be removed from the school site after completed the questionnaire. Finally, the questionnaire was distributed to the respondents in a free classroom setting.

\subsubsection{Scoring}

In coding the collected results, the researcher first sorted out negative items from each scale and assigned alternative scoring method (numerically), to simplify the data scoring tasks. Items negatively written were reversely coded. Then responses from the scales were properly filtered and coded to make ready for statistical processing. Each item was scored for each respondent, and then an average variable score for each individual was determined by averaging the item scores.

\subsection{Data Analysis}

Statistical Package for the Social Sciences (SPSS) version 20 computer software was used to enter, clean, and analyzes the quantitative data. Before proceeding with the actual statistical analysis, assumptions associated with the use of each of the analysis were checked. In addition, alpha value of 0.05 was determined for all significance tests.

After the data were coded and entered to the computer, different statistical analyses were made. To summarize the raw data, descriptive statistics such as frequency, percentage, mean, and standard deviation were computed. Then, to examine the interrelationship among variables (independent and dependent/outcome) inter-correlations were computed by using Pearson r. T-test was employed to investigate the mean difference on identity achievement by gender. Lastly, Analysis of variance (ANOVA) was used to crystallize the independent effects year of staying in college on the identity achievement as outcome variables. ANOVA was chosen due to the existence of one continuous dependent variable.

\section{Results}

Among 291 subjects, more than half $(177,60.8 \%)$ were female students while the rest $(113,39.2 \%)$ were male. The majority $140(48.1 \%)$ of participants age ranges from $18-20$, followed by $96(33 \%)$ respondents whose age ranges from 21-23 years and the remaining 24-26 were 55 (18\%). As far as their year of staying in college is concerned, most participants $(126,44 \%)$ were second year followed by first $(96,33 \%)$ and third year $(69,23 \%)$ students respectively.

Results show that $22.3 \%(n=65)$ of participants had low level of social support, $48.8 \%(n=142)$ had medium social support, and $28.9 \%(n=84)$ had high level of social support. In addition, $7.6 \%(\mathrm{n}=22)$ of participant's family had low socioeconomic status, $74.9 \% \quad(n=218)$ had medium socioeconomic status, and $17.5 \% \quad(n=51)$ had high socioeconomic status. These descriptive statistics explained by calculated mean, whether it is greater or lesser than the expected mean. In all variables, if calculated mean is below the expected mean represents low score and calculated mean equal or above the expected mean, represents high score in each variable. In relation to identity, the expected mean was 30 and the calculated mean is 41.021 . Those results indicate that all participants' scored more than the expected mean, so that, they were closer to the highest in their level.

Intercorrelation between the predictor and outcome variables

In research question two it is asked, "Is there a significant association between predictor variable (social support) and the identity status scores. The findings of this study apparently indicated the importance of social support for young adult's identity. The result of bivariate correlation between social support and identity achievement revealed significant positive relationship $(\mathrm{r}=0.499, \mathrm{n}=291, \mathrm{p}<0.01)$.

Gender and Year of Staying in College difference on Identity Achievement

An independent-samples t-test was conducted to compare the identity style for males and females. There was no significant difference in scores for males $(M=71.76, S D=$ 13.54) and females $[\mathrm{M}=71.26, \mathrm{SD}=11.66$; $\mathrm{t}(289)=0.332$, $\mathrm{p}=.05]$. An examination of the independent-samples t-test result between identity and gender indicated the absence of significant mean difference. A one-way between-groups analysis of variance was conducted to explore the impact of year of staying in college on identity achievement using functional identity style scale. Subjects were divided into three groups according to their year of staying in college (first year, second year and third year). There was no statistically significant difference at the $p<.05$ level in identity achievement scores for the three groups $[\mathrm{F}(2,238)$ $=0.08, \mathrm{p}=.05]$. The actual difference in mean scores between the groups was quite small. 


\section{Discussion}

The outcomes of the present study are going to be discussed based on the principal research questions raised earlier in this study. The questions were:

1) What is the status of identity achievement profile of young adult college students?

2) Is there statistically significant relationship between social support and identity achievement profile of young adult in college?

3) Does the identity achievement profile significantly vary across demographic variables including gender and year of staying in college?

\subsection{The Status of Identity Achievement}

In this section, the status of participants of the dependent variable was discussed in brief. The finding of this study revealed that most participants who were included in the study have favorable and healthy identity achievement. The overall mean score indicated greater score than the expected mean in relation to identity achievement. This showed that, achievement of identity is the prominent task of college aged students. Consequently, the finding of previously conducted researches and this study would be in support of other studies on identity achievement status of young adult students in college [15]; [34]. In this study, participants stated as they have good knowledge about their self, they were clear what will be in the future, they were self-committed to direct their goals.

\subsection{Intercorrelation Between the Predictor and Outcome Variables}

Based on this it can be concluded that students who have higher level of social support do have significantly higher level of identity achievement. Likewise, different scholars pointed out that opportunities offered by an individual's environment have a larger influence on the identity formation. Especially, the work of Marsha and Mark [36] clearly indicated that there were significant main effects of acquiring social support on the identity development among young adult college students. Para [37], also confirmed that the sources of support including family, peer and significant other appear to have the greatest influence on the formation of strong sense of identity. To strengthen the above most empirical findings consistently clarified as identity formation is believed to be influenced by maintaining relationships with sources of support than by individuation and is seen as providing a secure base for identity development. Therefore, one can realize from the analysis and discussions made in this study that social support has strong relationship with the achievement of identity of young adult students in college.

\subsection{Gender Difference on Identity Achievement}

An examination of the correlation result between identity and gender indicated the absence of significant relationship. Equivalently, according to Kroger [50], based on the review of empirical studies, rejected the idea of strong gender differences in both identities structure used in the identity formation process. Despite a clear conclusion about gender difference in identity formation, studies have shown the absence of gender difference in identity formation [32]. Moreover, Muss concluded that in most traditional domains of identity, male and female follow similar patterns of identity status. Others added that the timing of identity formation on both gender appeared to be about the same. More to the point Marcia cited in Temesgen [47] conducted a research on 80 participants and did not found any significant difference between males and females identity achievement. Unlike Yekoyealem [51], local researchers also found the same result with the present study [29], [47].

Year of Staying in College and Identity Achievement

As the finding of this study revealed, students from higher, medium and lower college year do not have significantly greater level of identity formation difference. However, previous findings spelled out as students college year was found to be potential contributor variable in explaining considerable variation of young adult students in college identity formation profile. Chickering and Reisser's theory of psychosocial development and Pamela \& Montenique, [36], stated that it is among second and third year college students identity more develops than freshman is. A possible explanation may be that, freshmen who just enter college from high school cherish a very idealistic expectation towards college life but only to discover reality is not the same thing as prior expectation. Coupled with differences in living environment, lifestyle and learning methods from those in high school, freshmen began to feel confused, perplexed and then have no sense of direction and purpose. With college life and learning continues, as well as their adaptation to the environment, college students gradually find the center of their own life and clear their objectives and directions after a year of exploration. So when sophomores being basically back to the right track, the second year is a relatively flat and busy time for them during their four years in college. Not only would college students in such stage work hard in studying, community activities, interpersonal relationships, love, cadres election of are also waving to them, which makes them feel fulfilled. Along with a deep exploration from their second year to the third year in college, confusion faced with college students is bound to increase, including problems of academic study, interpersonal relationships, love and other problems troubling them very much as well; in the meantime, what to do after graduation becomes an ineluctable problem, letting them suffer a new but different one with misery, confusion and perplexity from what they encounter in the first year in college. After a tough junior time, most of senior students have set up their own goals, such as taking part in postgraduate entrance examination, earning some certificates, finding a job or going abroad, with everything going step by step. At this time, there are less fickleness, depression, and madness, replaced by calmness in the face of future or a tranquil mentality even they feel confused [59]. The discrepancy of this finding with previously done researches can be due to many reasons. One 
probable explanation for this inconsistent result may be due to methodological limitation, including the instrument used for this study, unforeseen conditions while data were collected and the way this variable was treated. Above all, the homogenous nature of participants in their level of socioeconomic status takes the lion share for the presence of this discrepancy. Therefore, based on the finding of this study, it is impossible to generalize without further investigation on the issue.

\section{Conclusions}

An attempt was made to collect relevant information regarding the factors, which can either foster or hinder the effective achievements of healthy identity formation. Thus, based on the findings of the study, the following conclusion and suggestions forwarded as follows:

Majority of young adult students in college have moderate and closer to the highest level of identity achievement. Students who have higher level of availability of social support could have the opportunity to achieve their identity. The identity formation of young adults would be sensitive to developmental and social supports associated with the college environment and the existing social climate of the society. It was the strongest contributor in the identity achievement of young adult college students. Therefore, family, peers, relatives, teachers, counselor, and other significant persons should understand the importance social support in their identity profile.

There was no significant difference observed between male and female in their identity achievement. Year of staying in college was not found as a prominent factor in the identity achievement profile of young adult college students. In both cases, controversial and discrepant results found with the previously identified literatures. Thus, continuous and extensive research investigation should be done on gender and year of staying in college as a factor on identity style to validate this finding and make valuable generalization.

To identify other factors that can hold back the identity formation of young adult students in college, further studies should be carried out on the same area. As stated elsewhere, social support, gender, year of staying in college are not the only contributors to the outcome variables. Therefore, it would be hasty to arrive at the generalization that only these factors would predict the outcome variable. In addition to the above, further research should be directed toward identifying the role of optimism, self-efficacy, commitment and copping strategies as more powerful contributors in influencing the identity attainment of young adult college students. It helps to make more dependable generalization.

\section{References}

[1] Abera Tefery. (2010). The influence of inter ethnic attitude on inter-ethnic quality of interaction among Addis Ababa University of Oromo, Tigray and Amhara students. Unpublished MA thesis, Addis Ababa University. Institute of psychology
[2] Ann, D. and Patricia P. (2000). Educational connections, helping families identify appropriates the rapeutic options. Retrieved from, $\mathrm{http}: / / \mathrm{www}$.educationalconnections.com/service s.htm

[3] Arnett, JJ. (1997). Young people's conceptions of the transition to adulthood, University of Missouri, Journal of youth and society, 29, 13-23. Retrieved from DOI: $10.1177 / 0044118 X 97029001001$

[4] Arnett, JJ. (2000). Emerging Adulthood: a theory of development from the late teens through the twenties. American Psychologist Association. 55, 469-480 Retrieved from,

www.nlts2.org/reports/2005_04/nlts2_report_2005_04_refs.pd $\mathrm{f}$

[5] Arnett, JJ. (2004). Emerging Adulthood: The winding road from late teens through the twenties. Oxford University Press. Retrieved from www.oup.co.uk

[6] Arnett, JJ. (2007). Emerging adulthood: What is it, and what is it good for? Child Development Perspectives. Clark University. 1. 68-73, DOI: 10.1111/j.1750-8606.2007.00016.x

[7] Arnett, JJ. (2007). Handbook of socialization: theory and research. New York, Division of Guilford publication.

[8] Ashley, K, (n.d.), Predicting social support group membership, University of Nebraska Lincoln. Retrieved from http://psych.unl.ed

[9] Ashley, K, (n.d.), Predicting social support group membership, University of Nebraska Lincoln. Retrieved from http://psych.unl.ed

[10] Ayalu Reda, Asmamaw Moges, Birhanu Wondimagegn, Sibahtu Biadgilgn. (2012). Alcohol drinking patterns among high school students in Ethiopia: a cross-sectional study. National Center for Biotechnology Information, USA. DOI: 10.1186/1471-245812-213

[11] Basol, G. (2008). Validity and reliability of the multidimensionality scale of perceived social support. An International Journal. 36, 1303-1313. Retrieved from http://findarticle

s.com/p/articles/mi7398/is_10_36/ai_n32061595/?tag=content ;col1

[12] Bettina, F. Piko and Kevin, M. (2006). Socioeconomic status, psychosocial health, and health behaviors among Hungarian adolescents, University of Szeged, USA, Retrieved from, $\mathrm{http} / / /$ eurpub.oxfordjournals.org/

[13] Beverly, L. (2009). Student engagement for college students with the hidden disability of orthostatic intolerance. Doctoral dissertation. University of Toledo. Retrieved from, http://etd.ohiolink.edu/view.cgi?acc_num=toledo1262881229

[14] Carmen, L. (2010). Exploring the experiences of sexual stigma, gender non-conformity stigma and HIV-related stigma and their associations with depression and life satisfaction among men who have sex with men in South India. MA thesis. University of Toronto. Toronto. Retrieved from, https://tspace.library.utoronto.ca/bitstream/1807/26291/1/Logi e_Carmen_H_201011_PhD_thesis.pdf

[15] Chickering, A., \& Reisser, L. (1993). Education and Identity. ed 2nd. San Francisco: Josey Bass Retrieved from http://www.chrisnormile.com/studentaffairsconsulting/student development-theories/chickering 
[16] David N. \& Chava N., 1987, Research method in the social sciences $\left(3^{\text {rd }}\right.$ ed). St. New York Martin's Press, Inc.

[17] Demir, J. (2011). Functions of identity scale: Turkish validity and reliability. Educational Sciences: Theory \& Practice 11(2) • pp. 579-586, Istanbul University. Retrieved from, http://www.eric.ed.gov/PDFS/EJ927366.pdf

[18] Dereje Bekele, 2010, The relationship between social identity and interpersonal relationship of Addis Ababa University students. Unpublished MA thesis. Addis Ababa University, Addis Ababa

[19] Eric, K. Peter F, Leah G., \& Humphrey I. (2009). Chance capstone engaging Somali young adults in Cedar-Riverside: Opportunities for programming and collaboration, Humphrey Institute. Retrieved from, www.leadership.umn.edu/.../chance/.../Group_Draft_13_PF_E G_EK

[20] Erikson, E. H. (1971). Identity: Youth and crisis. London: Faber and Faber Ltd.

[21] Etaf, M. (2010). Social competence among the students of the university and relation to demographic factors. European Journal of Social Sciences. Tafila Technical University. 16(1). Retrieved from, http://www.eurojournals.com/ejss_16_1_15.pdf

[22] Green, M., Wheatley, M., John F., \& Aldava V. (1992). Stages on life's way Adolescents' Implicit theories of the life course, Pacific Graduate School of psychology, Journal of Adolescent research, 7(3), 364-381 Retrieved from http://www.jar.sagepub.com/content/7/3/364.full.pdf

[23] Kassahun Admassu. (2010). Navigating uncertainties: schooling and the transition to adulthood in Ethiopia". Doctoral dissertation. Brown University, Retrieved from, http://udini.proquest.com/view/navigating-uncertaintiesschooling-goid:763492416/

[24] Krejcie, R. V \& Morgan, D. W. (1970). Determining sample size for research activities. Educational and Psychological measurement Journal, 30, pp. 607-610. http://researchAdvoisors.com/tools/samplesize.htm

[25] Landino, R. (2006). Growth and change through the college years. Psych Central. Retrieved on May 30, 2012, from http://psychcentral.com/lib/2006/growth-and-changethroughthe-college-years/

[26] Mahmoud, J. (2011). The relationship of anxiety, coping, thinking style, life satisfaction, social support, and selected demographics among young adult college students. Doctoral dissertations. Retrieved from, http://uknowledge.uky.e $\mathrm{du} /$ gradschooldiss/128

[27] Marsha, J. \& Mark B. (2003). The relationship between the living arrangements of university students and their identity development, In J. Adelson (Ed.), Handbook of adolescent psychology. Vol. 38. pp. 159-187. Retrieved from, www.questia.com/googleScholar.qst?docId $=5002025157$

[28] Mebratu Bekele (2010). Career choice of students at preparatory schools in Wolayta zone. Unpublished MA thesis, Addis Ababa University, Addis Ababa

[29] Missaye Mulate. (2009). Identity status and sexual experiences among adolescent students in Debre Markos Town. Unpublished MA thesis. Addis Ababa University. Addis Ababa
[30] Muhammad R., \& Neelma S. (2010). Urdu translation and psychometric properties of social provision scale, Institute of Clinical Psychology University of Karachi-Pakistan, The International Journal of Educational and Psychological Assessment, Retrieved from http://tijepa.books.officelive.com/Documents/A3_V4_TIJEPA .pdf

[31] Mulugeta Dadi. (2010). Emotional intelligence and its link with some demographic variables and academic achievement among adolescents and young adults in Adama Town. Unpublished MA Thesis. Addis Ababa University. Addis Ababa.

[32] Muus, R. (1996). Theories of Adolescence. New York: McGraw-Hill

[33] National Center for Educational Statistics. (2008). "National education longitudinal study," third follow-up survey. Retrieved from http://nces.ed.gov/pubs98/yi/y9615a.asp

[34] NiiYii- L. (n.d.). Psychosocial Development of Taiwanese University Students, Center for Teacher Education, Counseling Center, National Tsing Hua University 101, Section 2 Kuang Fu Road, Hsinchu City, Taiwan 300. Retrieved from http://ir.lib.nthu.edu.tw/bitstream/987654321/12123/1/932413 H007007.pdf

[35] Pallant, F. (2005). SPSS survival manual: a step by step guide to data analysis using SPSS. $2^{\text {nd }}$ ed, Cataloguing-in Publication entry. Ligare, Sydney, Retrieved from, www.allenandunwin.com/spss.htm

[36] Pamela B., \& Montenique F. (2002). Negative life events and psychological distress among young adults, American Sociological Association, social psychology, 65(2), 186201, Accessed: 03/04/201204:33. Retrieved from http://www.jstor.org/stable/3090100

[37] Para, A. (2008). "The role of social support in identity formation: A literature review," Graduate Journal of Counseling, Psychology: 1(1), Retrieved from, http://epublications.marquette.edu/gjcp/voll/iss 1/9

[38] Pascarella \& Terenzini. (2005). Theories and models of student change in college, in how college affects students, A third decade of research by Ernest T. Jossey-Bass, San Francisco, Retrieved from, www.josseybass.com

[39] Patrice, A. (2007). Variables that predict development of purpose in traditional aged college students, Retrieved fromhttp://athenaeum.libs.uga.edu/bitstream/handle/10724/96 31/prince_patrice_a_200705_phd.pdf? sequence $=1$

[40] Schulenberg, J., O'Malley, P. M., Bachman, J. G. \& Johnston, L. D. (2000). "Spread your wings and fly the course of well-being and substance use during the transition to young adulthood. In: Crockett, L. J. and Silbereisen, R. K. (Eds.) Negotiating Adolescence in Times of Social Change, New York: Cambridge Univ. Press, 224255.

[41] Serafini, T. E., Maitland, S. B, \& Adams, G. R. (2006). The Functions of Identity Scale: Revisions, validation and model testing. Poster presented at the Biennial Meeting of the Society for Research on Adolescence, San Francisco. Retrieved from www.w3.fiu.edu/.../Serafini/Functions $\% 20$ of $\% 20 I d e n t i t y \% 20$ Scale 
[42] Settersten, J., \& Barbara R. (2010). What is going on with young people today? The future of children, transition to adulthood. Princeton University. 20(1), 19-41. Retrieved from http://www.jstor.org/stable/27795058

[43] Solomon Shiferaw, Mesganaw Fantahun, \& Abeba Bekele.(2006). Psychosocial problems among students in preparatory school, in Dessie town, North Western Ethiopia. Ethiopia Journal of Health Development; 20(1): 47-55. Retrieved from http://www.ajol.info/index.php/ejhd/article/viewFile/10011/22 64

[44] Taina, H. (2000). Psychosocial development and social support among adolescent visual impairment, University of Tampere, Academic dissertation, School of public health, department of Adolescence psychiatry, Finland retrieved from http://acta.uta.fi/pdf/951-44-4842-1.pdf

[45] Tam, C. (2008). Perceived social support, coping capability and gender differences among young adults, Sunway University College, Selangor Darul Ehsan. Retrieved from, http://www.scribd.com/doc/29136704/

[46] Tao S., Qi D., Michael W., Bruce H., \& Mark P., (2000). Social support: relations to coping and adjustment during the transition to University in the People's Republic of China, Journal of Adolescent Research, 15(123) DOI: $10.1177 / 0743558400151007$

[47] Temesgen Feyissa. (2010). The relationship between parenting style and identity formation of preparatory school students in Addis Ababa. Addis Ababa University. Unpublished.

[48] TePoel A., (2012). "Chancellor's scholars program: Exploring the transitional influence on freshmen college students". Educational Administration: Theses, Dissertations. Retrieved from,

http://digitalcommons.unl.edu/cgi/viewcontent.cgi?article $=10$ $89 \&$ context $=$ cehsedaddiss Tinakon

[49] Tinakon W, Nahathai W, \& Ruk. (2011). Reliability and validity of the multidimensional scale of perceived social support. Clinical Practice \& Epidemiology in Mental Health, Chiang Mai University. Retrieved from http://www.ncbi.nlm.nih.gov/pmc/articles/PM C3219878/pdf/CPEMH-7-161.pdf

[50] Wim, B. \&Inge, S. (2011). Does identity precede intimacy? Testing Erikson's theory on romantic development in emerging adults of the 21 st Century, Journal of Adolescent Research, 25(3) 387-415. DOI: 10.1177/0743558410361370

[51] Yekoyealem Dessie. (2005). The relationship between parenting style and identity style of secondary school and preparatory school adolescents at Debre Brihan. Unpublished MA thesis. Addis Ababa University. Addis Ababa.

[52] Yigzaw Kebede. (2002). Cigarette smoking and Khat chewing among college students in North West Ethiopia. Department of community health, Gondar College of Medicine Science. Ethiopia Journal of Health development. Retrieved from, http://www.ajol.info/index.php /ejhd/article/viewFile/9818/31243

[53] Yonas Mekonin, (2007). Assessment of the contribution of peer education among youth for HIV infection risk reduction (the case of family guidance Association Addis Ababa Branch, Kirkos youth center), Addis Ababa University, unpublished.

[54] Zimet, Dahlem, Zimet and Farley, (1998), Multidimensional scale of perceived social support, Journal of personality assessment, Retrieved from, http://www.yorku.ca/rokada/psyc test/socsupp.pdf

[55] Zimet, Dahlem, Zimet \& Farley, (1988), Psychometric characteristics of the multi-dimensional scale of perceived social support, Journal of personality assessment, 55, 610-617 http://www.yorku.ca/rokada/psyctest/socsupp.pdf

[56] Zimmer, J., \& Collins, W. (2003). Autonomy development during adolescence. In G. R. Adams \& M. Berzonsky (Eds.), Blackwell Handbook of adolescence. pp. 175-204. Oxford: Blackwell Publishers. Retrieved from, www.sdrs.info/docments/MSword/autonomy chapter.doc

[57] Ayalu Reda, Asmamaw Moges, Birhanu Wondimagegn, Sibahtu Biadgilgn. (2012). Alcohol drinking patterns among high school students in Ethiopia: a cross-sectional study. National Center for Biotechnology Information, USA. DOI: 10.1186/1471-245812-213

[58] Ezenna Michael Agwu, Stephen Draper, Mark De Ste Croix. Social Support, Body Image Perception and Depressive Symptoms, Among University Students in Nigeria, by Gender and Ethnicity. Science Journal of Public Health. Vol. 5, No. 3, 2017, pp. 263-274.doi: 10.11648/j.sjph.20170503.25

[59] Zhou Yongkang, Zeng Weixi, Hu Yalin, Wang Hui. Empirical Research on College Student's Role Identity Status in China. American Journal of Applied Psychology. Vol. 2, No. 6, 2013, pp. 94-100. doi: 10.11648/j.ajap.20130206.15 